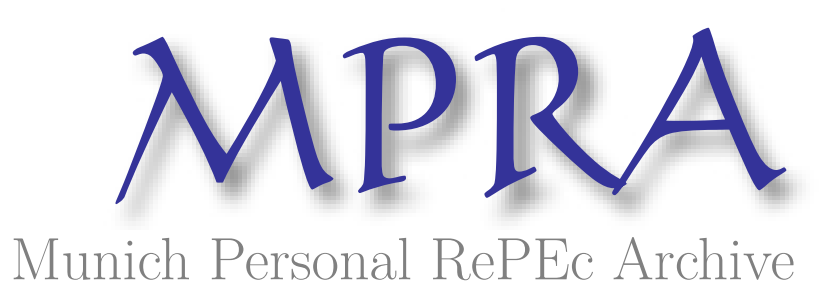

\title{
A micro-econometric model of a short run cost function with unobserved heterogeneity
}

\author{
Prentice, David \\ La Trobe University
}

March 2000

Online at https://mpra.ub.uni-muenchen.de/28682/

MPRA Paper No. 28682, posted 07 Feb 2011 00:07 UTC 


\section{A Micro-Econometric Model of a Short Run Cost Function with Unobserved Heterogeneity}

David Prentice

School of Business

La Trobe University, Bundoora, VIC, 3083.

March 2000

Phone: 0394791482

Fax: 0394791654

email: d.prentice@latrobe.edu.au

\footnotetext{
* This paper is a revised version of Chapter Three of my Ph.D. dissertation written at Yale University. I would like to thank my supervisors Steven Berry, Moshe Buchinsky and Joel Waldfogel for their advice and support. This paper has also benefited greatly from comments at various stages by Tom Crossley, Iain Fraser, Tue Gørgens, John Kennedy, Lisa Magnani, Gylfi Magnusson, Ariel Pakes and Rabee Tourky. Helpful comments were also received from participants in seminars at La Trobe University, Monash University, University of Melbourne, UNSW, University of Sydney, RSSS-ANU and Yale University. I would also like to thank Tony Salvage for assistance with the diagrams. I am most appreciative to Curtis Betts and the FW Dodge Co. for the use of the construction data. All errors remain my own responsibility.
} 


\section{Summary}

Unobserved plant level heterogeneity and discrete production processes can produce problems for estimation. A structural model of discrete production decisions by heterogeneous plants is constructed and, as a case study, estimated for the U.S. Portland cement industry. A new estimator is proposed to handle the discrete production process - for which the ordered probit is a special case. Data on firm survival and exit are used to adjust all input requirement coefficients for unobserved heterogeneity. The structural model is successfully estimated. Differences between many estimated coefficients and independent estimates from external sources are statistically insignificant. 


\section{Introduction}

The short run cost function plays a key role in estimating market power or predicting input and output decisions. Estimation in the new empirical industrial organization, and elsewhere, typically proceeds by assuming that the common short run marginal cost function is both convex and continuous in either all outputs or, as with hedonic cost functions, in product characteristics. However, recent work suggests models based on these assumptions are not always appropriate for empirical work. One set of papers demonstrates productivity and size varies substantially across plants within industries resulting in divergent responses to common shocks (e.g., Davis and Haltiwanger (1992)). Furthermore, not controlling for this heterogeneity results in biased estimation (Olley and Pakes (1996)). A second set of papers presents evidence that production is sometimes better characterised as a discrete rather than a continuous choice and that cost functions may be non-convex (e.g., Bresnahan and Ramey (1994)). If the cost function is severely misspecified then other results could be compromised.

In this paper, I specify a structural model of a plant short run marginal cost function in an industry featuring both plant level heterogeneity and discrete production decisions across multiple units. A new estimator is proposed to handle the discrete production decisions. Furthermore, the model is extended to deal with incomplete information about plant output and unobserved cost heterogeneity. In particular, plant exit and survival data is used to control for cost differences across operating plants. The structural model is estimated with a new unusually detailed dataset on the U.S. Portland cement industry. Estimates of some parameters of the cost function are found to not differ significantly from independent estimates obtained from trade journals and input consumption data.

The model estimated in this paper significantly improves on earlier work in three ways. First, the discrete production decision rule for multiple units is estimated more directly and completely than in Bertin, Bresnahan and Raff (1996). Second, input requirement coefficients are adjusted directly for unobservable plant level 
heterogeneity unlike in Olley and Pakes (1996) and Dionne et al (1998) where the effects of unobservable heterogeneity are introduced a more limited way. Finally, the methodology and model improves on earlier work by being implementable with datasets typically available to firms or consultants rather than specialized datasets such as census unit record data. Thus the model and technique are more broadly applicable. So, before applying standard techniques in industry analysis, the importance of plant heterogeneity and discrete production decisions should be checked. Where these conditions are important, the techniques presented in this paper can be applied.

The structural model is developed explicity for the U.S. Portland cement industry. This is done, in part, for clarity. It is important to stress, though, that the model and methodology can be applied to a broad set of industries which feature discrete production processes and multiple production units or plants, including steel and electricity generation. However, the cement industry requires less simplifying assumptions than typical when econometrically analyzing a manufacturing industry for several reasons. First, cement is essentially homogeneous. Second, it is produced by a relatively simple fixed proportions production process. Third, at least some of the most important sources of plant level heterogeneity are observable and they can be systematically included in both the modelling of the production decision and in the estimation of the short run cost function. Finally, the discrete production choice is a direct implication of the combination of the technology and the nature of competition in the industry.

In the next section, the short run cost function for a plant with multiple heterogeneous production units is derived yielding two discrete decision rules for production and retirement. The data are then introduced in Section 3. In Section 4, the model and data are reconciled and integrated producing a structural model for estimation, with a new estimator, of the short run cost function. Section 5 presents the results and in Section 6 some conclusions are presented. 


\section{The Short Run Cost Function}

Cement is the powder that is mixed with sand, aggregates and water to produce concrete. Most cement is a standard grey Portland cement effectively homogeneous across sellers. The primary use of concrete is in construction so cement consumption varies directly with construction activity. Demand is substantially separable across years because construction, in most parts of the United States, is concentrated in the summer and fall.

In subsequent subsections, the short run cost function for a cement plant is presented. Though such a function could easily be applied to similar industries. Then it is argued that the plant can be modelled as a price taker. This section concludes with two decision rules for the cement plant for production and retiring capital. The first decision rule provides the foundation for estimating the short run marginal cost function. The second rule is used to control for unobserved heterogeneity in productivity.

\subsection{The Short Run Cost Function ${ }^{1}$}

Manufacturing cement is a relatively simple process. Limestone, or a substitute, is quarried and ground into a raw mix. The raw mix is baked in a large kiln, producing small pellets known as clinker. Grinding the clinker and mixing it with gypsum produces cement. Once a kiln is installed, the input requirements per ton of cement are substantially fixed (e.g., Førsund and Hjalmarsson (1983); Das (1991a)). A kiln typically operates for decades and is then scrapped. The raw (material) grinding mills, the finish (clinker) grinding mills, distribution facilities, and other components of the cement plant are scaled around the kiln, or bank of kilns. The buildings and grinding mills are also usable for decades.

The cost function for the $\mathrm{n}^{\text {th }}$ of $\mathrm{N}$ kilns is derived as follows. Denote, $I\left(Q_{n}>0\right)$ as an indictator variable that takes the value 1 if the kiln operates and zero otherwise, $\alpha_{v n, p}$ as the vector of the input requirement coefficients for the $\mathrm{n}^{\text {th }}$ kiln which depend on its vintage, $v$, and process type, $p, w_{f}$ as the vector of fuel prices, $\alpha_{n, p}$ the vector of 
the input requirement coefficients which do not depend on kiln vintage, $w_{o}$ as a vector of other input prices and $f^{*} k_{n}$ as the kiln specific fixed costs. The kiln cost function is

$$
C\left(w, Q_{n}\right)=I\left(Q_{n}>0\right) \times\left\{w_{f}^{\prime} \alpha_{v n, p} Q_{n}+w_{n}^{\prime} \alpha_{o n, p} Q_{n}+f * k_{n}\right\}
$$

Indexing kilns by vintage and type reflects the emphasis placed on these characteristics in both the engineering and economics literature. There are three types of kilns: wet process, dry process, and preheater/precalciner process kilns. Both fuel and electricity requirements vary systematically by process. In particular, the wet process features the highest fuel requirements, then the dry process, and then the preheater/precalciner process kilns. Fuel consumption is also believed to increase with the age of the kiln because of embodied technological change and depreciation taking the form of increased input requirements (e.g., Das (1992); Rosenbaum (1994)). Hence, fuel coefficients increase with age as follows:

$\alpha_{v 1, p}<\alpha_{v 2, p}<\alpha_{v 3, p} \ldots$

Kiln differences lead not only to variation across plants but within plants as many plants operate multiple kilns of different vintages. ${ }^{2}$ Denote $\mathrm{Q}$ as plant output. Hence, from equations (1) and (2), the short run marginal cost function is as follows:

$$
m c= \begin{cases}w_{f}^{\prime} \alpha_{v 1, p}+w_{o}^{\prime} \alpha_{p}, & Q<k_{1} \\ w_{f}^{\prime} \alpha_{v 2, p}+w_{o}^{\prime} \alpha_{p}, & k_{1} \leq Q<k_{1}+k_{2} \\ \vdots & \sum_{i=1}^{n-1} k_{i} \leq Q<\sum_{i=1}^{n} k_{i}\end{cases}
$$

Hence marginal cost is a step function. For a plant with three kilns with capacities $k_{1}$, $k_{2}$ and $k_{3}$ plant marginal cost is depicted in Figure 1.

Fixed costs are composed of two components: start-up and expected shut down costs, and non-sunk capital costs. Expenditure on the plant and equipment is substantially sunk after installation because of the size and immobility of the kilns.

\subsection{The Decision Variable of the Plant}

The traditional view of the cement industry is that the combination of economies of scale with high transportation costs creates within the US a set of regional oligopolies (recent papers in this tradition include McBride (1983); Koller 
and Weiss (1989); Rosenbaum (1994)). However, whether the oligopolies are small enough to support market power is an empirical issue. The decreasing importance of domestic and international transportation costs is likely to have increased the size of the regional markets and increased the effect of potential competition from outside the markets (e.g. Peck and McGowan (1967); Prentice (1996)).

Hence, following Das (1992), the cement plant is assumed to be a price taker. The first implication of this assumption is that production and retirement decisions are made independently of decisions made for other kilns within the plant or across plants. Second, the production and retirement decisions simplify to two simple rules (see Das (1991a)). Denote $\beta$ as the discount factor, $T^{*}$ as the (endogenous) retirement date, if not retired in the current period, and $S V_{t}$ the scrap value at time t. The output and retirement decisions can be expressed as follows:

$Q_{n, t}= \begin{cases}k_{n} & \text { if } P_{t}-w_{f, t}^{\prime} \alpha_{v n, p}-w_{o, t}^{\prime} \alpha_{p}-f>0 \\ 0 & \text { otherwise. }\end{cases}$

Retire if $\mathrm{E}_{\mathrm{t}}\left(\sum_{j=t}^{T^{*}} \beta^{j-t}\left(P_{j}-w_{f, j}^{\prime} \alpha_{v n, p}-w_{o}^{\prime} \alpha_{p}-f\right) k_{n}\right)-S V_{t}<0$.

Equation (4) states if price exceeds the average cost of operating the kiln, the kiln operates at full capacity. Otherwise, nothing is produced. The production decision is a discrete choice that depends on price relative to average cost. Similarly, equation (5) states the kiln is retired if the expected present value of its operating is less than the current scrap value. These decision rules correspond to the output and shutdown rules in the continuous production decision case.

Furthermore, equation (4) in combination with equation (3) implies an ordering for the use of kilns - the Kiln Use Rule. In effect all of the kilns at a plant are ranked and operated in order of their efficiency. As the price of cement rises above the marginal cost of each kiln, that kiln is operated, in addition to all younger kilns at the plant. For a given price, the oldest kiln that is profitable to operate, is referred to as the marginal kiln for that plant. All younger kilns are operated, and all kilns older than the marginal kiln are idled. This is illustrated in Figure 1. With an output price, 
$\mathrm{P}$, the first two kilns, with capacities $k_{l}$ and $k_{2}$, feature marginal costs below $\mathrm{P}$ and are operated at full capacity. Kiln 2 is the marginal kiln. The third kiln, with a marginal cost greater than $\mathrm{P}$, is not operated.

Empirical support for the Kiln Use Rule is provided in Das (1992). After allocating plant output to kilns according to the Kiln Use Rule, most kilns are found to either operate at or near capacity or not at all.

The kiln retirement rule, equation (5), implies older kilns are retired before newer kilns, and wet and dry process kilns are retired before preheater/precalciner kilns. This pattern is generally observed over the sample period. However, there are striking examples of new kilns being closed, and kilns more than 50 years old continuing to operate. Anomalous plants must feature lower or higher than average marginal costs or kiln fixed costs due to plant specific factors such as the quality of their raw materials. The connection between plant productivity and plant exit has been highlighted in recent work. Griliches and Regev (1995), working with a panel of Israeli manufacturers, note plants closing during the sample period have significantly lower labor productivity than other plants. Olley and Pakes (1996) estimate a production function, including an adjustment for unobserved productivity differences based on plant investment, and achieve significantly better results. In Section 4.4, the kiln retirement rule is used to correct for the unobserved productivity differences across plants.

Finally, it is worth noting some further characteristics of the equilibrium underlying this characterisation of the industry. There may seem to be some tension between the assumption of price taking behavior and observed extensive heterogeneity as competition would drive out the more costly equipment and plants. Salter (1966) resolves this tension. With expenditure on capital equipment at least partially sunk, if demand exceeds capacity and price rises above average cost, Ricardian rents will be earned. In Figure 1, the rent earned by the firm on each kiln is equal to

$$
R T_{n}=\left(P-w_{f}^{\prime} \alpha_{v n, p}-w_{o}^{\prime} \alpha_{p}\right) k_{n}-f * k_{n}
$$


Unless entrants expect the rents subsequently earned by the kiln (or plant) will exceed the sunk capital costs entry will not occur and there will be a price taking equilibrium, with some plants earning Ricardian rents.

Specifying a complete theoretical expression for the Ricardian rents requires specifying a general equilibrium model of the national market which is beyond the scope of the paper. The rents depend on the characteristics of the kiln, the locational advantage of the plant, and demand (see also Lindenberg and Ross (1981); Alchian (1987)). A reduced form expression is presented in Section 4.4.

\section{The Data}

To estimate the decision rule for the plant, the operating status of each kiln and a set of explanatory variables are required. The sample features an observation for each plant for each year the plant is operable from 1977 to 1992. In this section, the nature and sources of the data used in this paper are briefly described. First, the basic set of data is described. The second subsection contains an outline of the method used to extract the sample of the operating status for each kiln in each year and the characteristics of the sample.

\subsection{The Nature of the Data}

Four broad sets of data are required: (1) prices of inputs, output and imported cement (2) quantity of clinker produced (3) kiln and plant characteristics (4) quantity of construction.

The price of cement, quantity produced of clinker and average number of kiln maintenance days are obtained from the annual US Bureau of Mines Minerals Yearbooks. Data on these variables are published for aggregates of small groups of plants, usually adjacent to one another. The modal plant number for these aggregates is 4 with $85 \%$ of the region years featuring 6 plants or less. The modal number of kilns per group is 7 with $82 \%$ of the region years featuring 13 kilns or less. The yearbook also contains the price of limestone (by state or substate) and import prices. ${ }^{3}$

The prices of other inputs, electricity, fuel and labor are obtained from various US government reports. Again, where possible, for all states except Pennsylvania, 
Texas and, to a lesser extent, California, these are aggregates over relatively small numbers of plants or else averages across broader groupings. ${ }^{4}$

Plant and kiln characteristics are obtained from the annual Portland Cement Association Plant Information Summary. This directory includes kiln capacities, vintages, primary and supplementary types of fuels used and ownership. The directory entries are crosschecked against the Minerals Yearbook regional plant and kiln counts, trade journal reports and company annual reports.

Finally, the annual value of construction contracts data (by state) is obtained from FW Dodge. This is deflated by the state construction price index constructed by the author (see Prentice (1997) for more details).

It is important to note that all of this data is available to firms in the industry. The government data is publically available. The Plant Information Summary and construction data, are compiled explicitly for sale to industry participants and other interested parties. Hence the model presented in Section 4 is usable by a firm or consultant.

The data is summarized in Table 4 including the variables required for controlling for Ricardian rents and unobserved heterogeneity across firms. These variables are discussed in Sections 4.4 and 4.5.

The next step in assembling the data is to assign input and output prices, and import prices, to plants. This yields a plant level data series by matching the state and Minerals Yearbook region prices to the plants located within the relevant areas. For assigning fuel prices to plants, the directory fuel reports are used unless contradicted by a more reliable source.

At this point it is worth comparing this new dataset with those used by earlier authors. This paper uses relatively disaggregated data rather than plant level data available to Das ((1991a);(1991b)). Rather than using quantities of inputs and outputs to estimate input requirement coefficients, as was done by Bertin, Bresnahan and Raff (1996) and Das ((1991a;(1991b)), input and output prices are used. This makes the problem more challenging as unlike input and output quantities, prices are determined 
by factors independently of the technological characteristics of the firm. Estimating input requirement parameters from input and output prices relies on duality relationships. ${ }^{5}$ This dataset is, then, more like those used by Prentice (1996) and Rosenbaum (1994).

This dataset improves on earlier data sets in two respects by including state limestone price and wage rate series. ${ }^{6}$ The relatively disaggregated series constructed for this paper are the best available series as plant level series are unavailable.

\subsection{Calculating Kiln Operating Status}

The operating status of each kiln cannot be determined by inspection of the regional clinker output data (unlike for the steel mills in Bertin, Bresnahan and Raff (1996)). So an algorithm is constructed to infer for each kiln at each plant whether the kiln operated, did not operate or if its status was unknown. The algorithm is presented in Table 1. The algorithm assumes the Kiln Use Rule holds at each plant but not across plants. This is because, kilns of similar ages at different plants may have different costs, because of different maintenance policies or raw material qualities, so their operating status may differ.

The algorithm yields observations for 2154 marginal kilns (each one per plant per year). All plants that featured kilns both operating and not operating, with the differences in their vintages being less than or equal to two years, are deleted. One plant featuring an unusual combination of processes, vintages and capacities is also deleted. This leaves 1999 observations. The outcome for each plant can be characterised into one of four groups, as recorded in Table $2 .^{7}$

Table 3 demonstrates the different processes and vintages are all represented in the sample.

\section{The Econometric Model}

In this section, the model presented in Section 2 is reconciled with the data to yield a structural model of the short run cost function. Beginning with the production decision rule, equation (4), it is argued that there is a common error term across the kilns at a plant. This means for each plant the relevant observation is that for the 
marginal kiln. The likelihood function for a new estimator required for this model is derived. Then it is demonstrated that with some strong assumptions this model yields the standard ordered probit. In Sections 4.4 and 4.5 it is discussed how to control for unobserved heterogeneity and Ricardian rents.

\subsection{Estimating a Cost function for a Discrete Production Process.}

The basic equation upon which estimation is based is equation (4). Denote $\rho_{t} k_{n}$ as unobserved costs of operating the $\mathrm{n}^{\text {th }}$ kiln at the $\mathrm{i}^{\text {th }}$ plant. The set of decisions for a plant with $\mathrm{N}$ kilns, ordered, according to the kiln use rule, from 1 to $\mathrm{N}$, can be expressed as follows:

$$
\begin{aligned}
& I_{1}=1 \text { if } P-w_{f}^{\prime} \alpha_{v 1, p}-w_{o}^{\prime} \alpha_{p}-f-\rho_{i}>0 \\
& I_{2}=1 \text { if } P-w_{f}^{\prime} \alpha_{v 2, p}-w_{o}^{\prime} \alpha_{p}-f-\rho_{i}>0 \\
& \vdots \\
& I_{N}=1 \text { if } P-w_{f}^{\prime} \alpha_{v N, p}-w_{o}^{\prime} \alpha_{p}-f-\rho_{i}>0
\end{aligned}
$$

The per unit unobservable costs $\rho_{i}$ are assumed to be plant specific rather than kiln specific. This is because the likely three largest components are most likely plant specific than kiln specific

First, raw materials, other than limestone, are either quarried locally or purchased externally. Hence the prices for these are unlikely to vary with the characteristics of the kiln. Second, the extent of maintenance varies with the expected life of the plant, which is determined by the quality of the raw materials and expected demand. Third, selling and distribution costs vary with the type and location of the customer. The second two are likely to be increasing in kiln capacity.

Estimation requires a distributional assumption on these unobserved costs. For the $\mathrm{n}^{\text {th }}$ kiln at the $\mathrm{i}^{\text {th }}$ plant:

$k_{n} \rho_{i} \sim N\left(k_{n} \mu, \sigma^{2} k_{n}^{2}\right)$

While equation (4) could be estimated as a probit, with a sample of all operable kilns, the correlation in the error terms of kilns at the same plant is likely to yield inconsistent estimates. It is now demonstrated that, instead, the appropriate sample is composed of, for each plant operable in each year, the observation, 
associated with the marginal kiln. The likelihood function for estimating the short run cost function is then developed. To aid the discussion, Figure 2 which contains a density function for $\rho_{i}$ when the plant has four kilns, is used. Along the horizontal axis is the series of returns to operating each of the kilns. Costs that do not vary with the kiln are removed for clarity. The return furthest to the right is that for the newest kiln, denoted (A). Moving left along the horizontal axis are the returns for the second (B), third (C) and fourth (D) ranked kilns.

It will now be demonstrated that there are four cases that occur. The first case is that all kilns are operated. In this case $\rho_{i}$ is low enough that even the $\mathrm{N}^{\text {th }}$ kiln is profitable to operate. The $\mathrm{N}^{\text {th }}$ kiln is then the marginal kiln. The case of all kilns operating occurs if $\rho_{i}$ is to the left of (D). The probability of observing all kilns operating is given by:

$\Phi\left(P-w_{f}^{\prime} \alpha_{v 4, p}-w_{o}^{\prime} \alpha_{p}-f \geq p_{i}\right)$

The second case occurs is if $n^{*}$, where $0<\mathrm{n}^{*}<\mathrm{N}$, kilns operate. If $\rho_{i t}$ is between (B) and $(\mathrm{C})$ then the return on the second (marginal) kiln is positive but return on the third kiln is negative so it is not operated. The probability of observing two out of four kilns operating is given by:

$\Phi\left(P-w_{f}^{\prime} \alpha_{v 2, p}-w_{o}^{\prime} \alpha_{p}-f \geq \rho_{i}\right)-\Phi\left(P-w_{f}^{\prime} \alpha_{v 3, p}-w_{o}^{\prime} \alpha_{p}-f \geq \rho_{t}\right)$

The third case occurs if no kilns are operated i.e. the plant is idled but not closed. To continue the example, if $\rho_{i}$ is to the right of (A) then no kilns are operated as the return on operating the lowest cost kiln is negative and all kilns ranked below also features negative returns. The probability of observing this outcome is:

$\Phi\left(P-w_{f}^{\prime} \alpha_{v 1, p}-w_{o}^{\prime} \alpha_{p}-f<p_{i}\right)$

The fourth broad case occurs when the marginal kiln cannot be identified by the algorithm used in section 3.2. There are two sub-cases, best illustrated by continuing the example of Figure 2. First consider if it is known that the first kiln operates but not whether any additional kilns are or are not operating. In this case $\rho_{i}$ could take any value to the left of (A). So the probability of observing kiln $n^{\prime}$ operating, but the marginal kiln is unknown is given by: 
$\Phi\left(P-w_{f}^{\prime} \alpha_{v n^{\prime}, p}-w_{o}^{\prime} \alpha_{p}-f \geq p_{i}\right)$

Note that the expression for this case is identical to the case where all kilns are operating except that instead of kiln $\mathrm{N}$ being used, the highest ranked kiln known to be operating is used $n^{\prime}$. So these observations are grouped with case one.

In some cases, there is more information - some kilns are known to operate and other kilns are known not to operate, but the marginal kiln is unknown. In Figure 2, if it is known that the first kiln operates and the fourth kiln does not operate, but it is unknown whether the second or third kiln is the marginal kiln, the relevant comparison is between kilns one and four. If it is known that kiln $n^{\prime}$ operates and kiln $n^{\prime}+j$ does not operate, but the operating status of kilns ranked in between $n^{\prime}$ and $n^{\prime}+j$ are unknown, the probablity of observing this case is:

$\Phi\left(P-w_{f}^{\prime} \alpha_{v n^{\prime}, p}-w_{o}^{\prime} \alpha_{p}-f \geq \rho_{i}\right)-\Phi\left(P-w_{f}^{\prime} \alpha_{v\left(n^{\prime}+j\right), p}-w_{o}^{\prime} \alpha_{p}-f \geq \rho_{i}\right)$

The likelihood function for this problem is then constructed as follows. Each observation (the marginal kiln for each plant in each year the plant is operable) can be classified as fitting into one of the four cases just considered: (1) all kilns operating with certainty or an intermediate number of kilns operating with uncertainty as to whether more kilns operate, (2) an intermediate number of kilns are operating at the plant with certainty, (3) no kilns are operating at the plant with certainty, and (4) some kilns are known to operate, some are known not to operate but the marginal kiln is unknown.

The log likelihood function is then just the sum of the logged probabilities associated with each of these cases:

$$
\begin{gathered}
\sum_{i \in 1} \ln \Phi\left(P-w_{f}^{\prime} \alpha_{v n, p}-w_{o}^{\prime} \alpha_{p}-f \geq p_{i}\right)+ \\
\ell=\sum_{i \in 2} \ln \left(\Phi\left(P-w_{f}^{\prime} \alpha_{v n, p}-w_{o}^{\prime} \alpha_{p}-f \geq p_{i}\right)-\Phi\left(P-w_{f}^{\prime} \alpha_{v n+1, p}-w_{o}^{\prime} \alpha_{p}-f \geq p_{i}\right)\right)+ \\
\sum_{i \in 3} \ln \Phi\left(P-w_{f}^{\prime} \alpha_{v 1, p}-w_{o}^{\prime} \alpha_{p}-f<p_{i}\right)+ \\
\sum_{i \in 4} \ln \left(\Phi\left(P-w_{f}^{\prime} \alpha_{v n, p}-w_{o}^{\prime} \alpha_{p}-f \geq p_{i}\right)-\Phi\left(P-w_{f}^{\prime} \alpha_{v n+j, p}-w_{o}^{\prime} \alpha_{p}-f \geq p_{i}\right)\right)
\end{gathered}
$$

Note that though this structural model has been developed for a cement plant, the information requirements are such that it can applied in any industry that features 
firms with multiple production units, with discrete production decisions. Furthermore, the model also handles the realistic case where the firm has information on its competitors characteristics, but not their production decisions.

\subsection{Comparison of this estimator with other estimators.}

Under certain restrictions, the log likelihood function (13) is equivalent to that for the standard ordered probit as described, for example, in Greene (1993).

First consider the average return expression in equation (4) and note how it is used in equations (8) - (12). In each expression there is a common component $\left(P-w_{o}^{\prime} \alpha_{p}-f\right)$ and a kiln specific component $w_{f}^{\prime} \alpha_{v n, p}$. The kiln specific components are generalized versions of the thresholds in the ordered probit. In particular, if these components are constant across time, across plants, and furthermore, each plant has the same number of kilns, these kiln specific components can be estimated as constant thresholds in a standard ordered probit. Furthermore, if there is no uncertainty about the operations of the kilns, the log likelihood function in this case reduces to that for a standard ordered probit. ${ }^{8}$

However, such restrictions are not appropriate for this dataset as the number of kilns differs across plants and the vintage and fuel costs vary over time. This estimator, then, is sufficiently general and practical for estimating short run cost functions in a variety of situations.

\subsection{Specifications for Estimation}

In this subsection, the three specifications of the cost function to be estimated are described. The first specification, referred to as the General specification, is as just described, based on log likelihood function (13). This specification includes, as in previous work, adjustments for vintage and process, and, for the first time, changes in union bargaining outcomes.

In Table 5 further information is presented on controlling for the following: how electricity requirements vary with kiln process and how fuel requirements alter with vintage. For flexibility, but also to capture the relative productivity of surviving kilns, the fuel coefficient is modelled as a quadratic function of the vintage of the kiln. 
An attempt was made with an exponential specification but, even with well-behaved simulated data, there were problems with convergence. The quadratic seemed the best alternative to capture any non-linear relationship between fuel consumption and vintage.

Furthermore, to attempt to capture productivity improvements following the effective collapse of a strong trade union in the industry (Northrup (1989)), a scaled trend is introduced. Finally, as discussed in sections 4.4 and 4.5, variables and terms are introduced to control for unobserved heterogeneity across plants and to allow for Ricardian rents.

The estimated coefficients may exceed industry averages, to be described in more detail below, if there are significant components of the unobserved costs that include labor, limestone, electricity and fuel, which cannot be ruled out. ${ }^{9}$

4.4 Controlling for unobserved heterogeneity across plants.

In section 2.2, it is noted that there are not infrequent examples of kilns not being closed according to the kiln retirement rule, on the basis of their observable characteristics. This suggested they had unobservable productivity differences. In this section, a method to control for unobservable productivity differences is suggested.

First, define plants that closed earlier than would be expected by the vintage of their kiln, relative to that of their neighbours as Exiters. Plants that remained open with relatively old kilns are defined as Survivors. The second specification, to be referred to as the Heterogeneity specification, allows for differences in the input requirement coefficients of Exiters and Survivors.

Before discussing the construction of the survivor and exiter variables, the nature of a near plant needs to be defined. If five or more plants are within 200 miles of a plant, the five closest to the plant are considered near. The 1977 Census of Transportation reports most cement is shipped within 200 miles of a plant. If there were between one and four plants within 200 miles, these are considered the near plants. If there are no plants within 200 miles, no near plant exists. 
To determine whether a plant was an exiter or a survivor or neither, the following process was used. The average vintage was calculated for near plants, $\bar{V}_{\text {near }}$. A plant was then termed an exiter if at any time during the sample period, the ratio of the vintage of its first kiln to this average was less than one. A plant was termed a survivor if for the whole sample period its vintage was always greater than the average. The Survivor and Exiter variables, $S R$ and $E X$, are then defined as follows:

$S R=D_{S V} \min _{t \in T^{\prime}}\left(\right.$ Vintage $\left./ \bar{V}_{\text {near }, t}\right)$

$E X=D_{E X} \operatorname{mean}_{t \in T}\left(\right.$ Vintage $\left./ \bar{V}_{\text {near }, t}\right)$

where $T^{\prime}$ and $T$ are the lifetime, within the sample period, of the kiln, and the whole sample period respectively, and $\mathrm{D}_{\mathrm{SV}}$ and $\mathrm{D}_{\mathrm{EX}}$ are dummies for survivor and exiter plants.

While Olley and Pakes (1996) controlled for unobserved heterogeneity using investment expenditure, the heterogeneity was confined to an autonomous productivity term. In Dionne et al (1998) unobserved heterogeneity is introduced through random effects. This paper improves on both of these approaches by allowing all input requirements coefficients to vary when controlling for unobserved heterogeneity.

A potential problem is that the kiln retirement decision, equation (5), is determined, in part, by unobserved differences in kiln fixed costs. But, this effect is unlikely to be econometrically important because the two central assets of the cement plant - the kiln and raw materials reserves - can last for decades. With the fairly complete coverage of inputs and prices in the cost function, it is unlikely that current unobserved fixed costs would be significantly correlated with the decision to close the plant.

\subsection{Controlling for Ricardian rents.}

The third specification, to be referred to as the Rents specification, includes both the adjustments in the Heterogeneity specification and an adjustment for Ricardian rents. The mean for the plant specific errors is left unspecified in (7) because of the possibility of Ricardian rents being earned as described in Section 2. 
While a formal expression is not possible, it is expected the rents vary positively with demand, $D$, the price of imported cement, $P_{m}$, the distance from domestic competition, $D F C$, the distance from import competition, $D F C D$ and negatively with vintage, Vintage. A reduced form expression for the Ricardian rents is reported in Table 5.

\section{Results}

The results of estimating the three specifications are discussed as follows. First, the estimates of the input requirement coefficients in the General and Heterogeneity specifications are presented, followed by a discussion of the effects of controlling for Survivors and Exiters. Finally, the effects of including variables to capture the Ricardian rents are discussed.

In Table 6 industry averages of the input requirement coefficients followed by estimates obtained from each of the three specifications are presented. The industry averages are calculated from national input consumption and production statistics from the Bureau of Mines Minerals Yearbooks or, for fuel consumption, from 19771988, from surveys reported therein. As long as there is not too much dispersion in the distribution, these averages can be used as a benchmark for assessing the reasonableness of the estimates. While it is unlikely the estimated coefficients are exactly the same as these averages it is expected that the differences between them and the industry averages are statistically insignificant. For each variable the coefficient value, the standard error (in parentheses) and the t-statistic are reported.

The estimated limestone and electricity requirement coefficients are typically much greater than the industry averages, though the differences, for several of these coefficients, are statistically insignificant. The relative sizes of the estimated coefficients for electricity by process for the first two specifications are also counter intuitive though, again, the differences are statistically insignificant. The coefficients on labor, before the change in bargaining, are more satisfactory in that they are not significantly different from the industry averages but they are also not significantly different from zero. 
The standard errors of the regressions for the General and Heterogeneity specifications are relatively high. With annual average real prices of cement varying between $\$ 70.11$ and $\$ 41.02$, standard errors in the low to mid twenties seem too large, suggesting considerable variation is not being picked up by the model. A likelihood ratio test shows introducing the additional variables in the Heterogeneity specification results in a significant improvement on the General specification.

On first inspection, the estimates of the fuel requirement coefficients do not appear promising. For all three processes, while the fuel requirement increases, at a decreasing rate, with the vintage of the kiln, the estimated fuel requirement for a new kiln is negative. Though not encouraging, this may be less of a problem than it first appears as, for example, there are very few wet and dry kilns less than 20 years old. In particular, the estimated fuel requirement coefficients need to be examined across the relevant set of vintages. First, note the maximum fuel requirements for the dry, wet and preheater processes are 10.18, 7.16 and 3.62 million BTU per short ton (for kilns built in 1926). The dry process maximum is quite plausible but the maximums for the other two processes seem too low.

To evaluate these estimates more thoroughly, comparisons of the estimated coefficients with average actual requirements coefficients for various vintages were made. Estimates of fuel requirements coefficients for new kilns built during the 1950s through to the 1980s were collected from the industry trade journals, Rock Products and Pit and Quarry. Where estimates for at least three different plants were available, F-tests were then performed to compare the average actual coefficients with the estimated coefficients. The sample, vintage effects and the results of the F-tests are summarized in Table 7.

The results of these tests are similar to those for the other estimated coefficients. For most cases the values of the estimated coefficients are different from the trade journal average but, with the imprecision of the estimates, the differences are not statistically significant. This appears to be less of a problem for the dry and wet processes than the preheater/precalciner process. But, in general, the quadratic 
functional form appears to be too restrictive to capture the variation in fuel requirements with vintage. Furthermore, a common vintage effect may also not be appropriate - especially for the preheater/precalciner kilns.

For labor requirements, after the change in bargaining arrangements, statistics similar to those calculated in Table 7 are calculated, adding in just the, near significant, squared component of the coefficient. The results are similar with the implied increase in productivity being too large and occurring too quickly. From four (General) to six (Heterogeneity) years after the change the estimated labor requirements coefficients are negative.

Next the adjustments to the input requirement coefficients for the different requirements for survivor and exiter plants are summarized in Table 8. The survivor and exiter adjustment coefficients are tested for being significantly less than and significantly greater than zero where applicable.

Though introducing these variables significantly improved the specification, none of the individual coefficients are significantly different from zero in the hypothesized direction. The coefficient on electricity for the exiters is even significantly negative though this may reflect that low electricity consuming wet process plants were exiting early in the period. The sizes of the fuel coefficients for the survivors and exiters are plausible, though both are imprecisely estimated.

Finally, the effects of controlling for Ricardian rents are considered. Though a likelihood ratio test results in a significant improvement of the specification, the standard error on the regression increases considerably. The estimated standard error was expected to decrease if the large size of the standard error in the earlier specifications was due to failing to capture variations in rents. Furthermore, with the exception of limestone, the sizes and signs of the input requirement coefficients all become much less plausible. The value of the constant term is unreasonably high. Likewise the sizes of the coefficients on the adjustment coefficients for survivors and exiters are less plausible. The coefficients on the rental variables are all insignificant. 
The result of the likelihood ratio test suggests something is being picked up but it does not appear to be Ricardian rents.

To sum up, there are two features of the results that are encouraging and one less encouraging. The first encouraging feature is that the specification is basically supported by the data as the new estimator is successfully estimated. The second encouraging feature is that many of the estimated coefficients are not significantly different from the industry averages. The less encouraging feature is that the differences from the industry averages seem too large to be attributed to a nonsymmetric distribution of coefficients. Perhaps the most problematic component is the estimated fuel requirement coefficients. They are plausible over certain ranges of vintages, especially for the wet and dry process kilns. However, the quadratic relationship with vintage appears to be too restrictive. Introducing adjustment coefficients for survivor and exiter plants significantly improves the specification as a whole but the individual adjustment coefficients are not significantly different from zero as hypothesized. Finally, introducing the reduced form measure of Ricardian rents also improves the specification as a whole, but the additional variables are insignificant and the plausibility of the results in general deteriorates, which suggests this is the least successful component of the estimation. Collinearity may be a problem here.

So, for future work, there are several ways in which the specification could be improved. First, a more flexible specification of the relationship between fuel consumption and kiln vintage could be used. Second, alternative specifications of the rent variables could be introduced. Third, the specification of the variance could be adjusted to control for the effects of exit and entry.

There are echoes of these findings in earlier work. Rosenbaum (1994) reported negative coefficients on a measure of vintage (which would trend downwards in his sample) and on wage rates. It would be interesting to see if Rosenbaum's measure of wages was also trending downwards. The use of the earlier part of the sample period may have avoided this problem with fuel prices. Prentice (1996), for the same sample 
period, had reversed coefficient sizes on variables capturing the interaction of fuel prices with process types. Das (1991a) had a constant term that was too high. Also, her results, using the prices data, improved when she shifted from using a logit to a semi-parametric estimation technique. The work of Rosenbaum and Das, to a certain extent, through their different sample periods, may have been insulated from the problems with either specification or unobserved variables that seem to be a problematic feature of these results.

\section{Conclusion}

This paper presents a structural model of a short run cost function for an industry with two features, recently highlighted in the literature, that make using existing techniques problematic: discrete production decisions and unobserved heterogeneity. Handling discrete production decisions requires a new estimator, of which the ordered probit is a special case. This estimator is extended to handle incomplete information on firm production decisions - a realistic constraint on firms and consultants. Data on plant survival and exit is used to adjust all input requirement coefficients for unobserved heterogeneity in productivity. The structural model is successfully estimated using a new dataset on the U.S. Portland cement industry. Furthermore, many of the estimates of the coefficients of the cost function are not significantly different from independent estimates derived from trade journals and input consumption statistics. However, the differences between the estimates and the industry averages are too great to be completely comfortable. This, with the mixed success in controlling for unobserved heterogeneity and Ricardian rents, suggests that though the approach taken in this paper is promising more work needs to be done. 


\section{References}

Alchian, A. (1987), 'Rents', in J. Eatwell, M. Milgate and P. Newman (eds.) The New Palgrave: A Dictionary of Economics, Vol. 4, Macmillan, London.

Bertin, A. L., T. F. Bresnahan and D. M.G. Raff (1996), 'Localized Competition and the Aggregation of Plant-level Increasing Returns: Blast Furnaces 1929-1935', Journal of Political Economy, 104, 241-266.

Bresnahan, T. F. (1989), 'Empirical Studies of Industries with Market Power', in R. Schmalansee and R. D. Willig (eds.), Handbook of Industrial Organization, Vol. 2, North-Holland, New York.

Bresnahan, T. F. and V. A. Ramey (1994), 'Output Fluctuations at the Plant Level', Quarterly Journal of Economics, 109, 593-624.

Bresnahan, T. F. and P. C. Reiss (1990), 'Entry in Monopoly Markets', Review of Economic Studies, 57, 531-553.

Bureau of Labor Statistics (various years), Employment, Hours and Earnings, G.P.O, Washington DC.

Bureau of Mines (1976-1992), chapters on Cement and Crushed Stone in Minerals Yearbook, G.P.O, Washington DC.

Capone Jr., C. A. and K. G. Elzinga (1987), 'Technology and Energy Use Before, During and After OPEC: The U.S. Portland Cement Industry', The Energy Journal, 8, 93-112.

Das, S. (1991a), 'A semiparametric structural analysis of the idling of cement kilns', Journal of Econometrics, 50, 235-256. (1991b), 'Estimation of Fuel Coefficients of Cement Production: A FixedEffects Approach to Nonlinear Regression', Journal of Business \& Economic Statistics, 9, 469-474. (1992), 'A Microeconometric Model of Capital Utilization and Retirement: The Case of the U.S Cement Industry', Review of Economic Studies, 59, 277-297. 
Davis, S. J. and J. Haltiwanger (1992), 'Gross Job Creation, Gross Job Destruction, and Employment Reallocation', Quarterly Journal of Economics, 107, 819863.

Dionne, G., R. Gagné, C. Vanasse (1998), 'Inferring technological parameters from incomplete panel data', Journal of Econometrics, 87, 303 -327.

Department of Commerce (various, a), County Business Patterns, G.P.O, Washington DC.

Department of Commerce (various, b), U.S. Census of Manufactures, G.P.O, Washington DC.

Department of Energy (various), State Energy Price and Expenditure Report, G.P.O, Washington DC.

Forsund, F. R. and L. Hjalmarsson (1983), 'Technical Progress and Structural Change in the Swedish Cement Industry 1955-1979', Econometrica, 51, 1449-1467.

Greene, W. H. (1993), Econometric Analysis, $2^{\text {nd }}$ Edition, Macmillan Publishing Company, New York.

Griliches, Z. and H. Regev (1995), 'Firm Productivity in Israeli Industry 1979-1988', Journal of Econometrics, 65, 175-203.

Koller II, R. H. and L. W. Weiss (1989), 'Price Levels and Seller Concentration: The Case of Portland Cement' in L. W. Weiss (ed.), Concentration and Price, MIT Press, Cambridge.

Lindenberg, E. B. and S. A. Ross (1981), 'Tobin's q Ratio and Industrial Organization', Journal of Business, 54, 1-32.

McBride, M. E. (1983), 'Spatial Competition and Vertical Integration: Cement and Concrete Revisited', American Economic Review, 73, 1011-1022.

Northrup, H. R. (1989), 'From Union Hegemony to Union Disintegration: Collective Bargaining in Cement and Related Industries', Journal of Labor Research, 10, $339-376$.

Olley, G. S. and A. Pakes (1996), 'The Dynamics of Productivity in the Telecommunications Equipment Industry', Econometrica, 64, 1263-1297. 
Peck, M. J. and J. J. McGowan (1967), 'Vertical Integration in Cement: A Critical Examination of the FTC Staff Report', Antitrust Bulletin, 12, 505-531.

Peray, K. E. (1986), The Rotary Cement Kiln, $2^{\text {nd }}$ Edition, Chemical Publishing Co., New York.

Portland Cement Association (1974-1992), U.S. and Canadian Portland Cement Industry: Plant Information Summary, Portland Cement Association, Skokie.

Prentice, D. (1996), The Dramatic, Mysterious Increase in Imports of Portland Cement into the U.S., mimeo, Yale University. (1997), Import Competition in the U.S. Portland Cement Industry, Ph. D. Thesis, Yale University. (1998), A microeconometric model of a short run cost function with unobserved heterogeneity, La Trobe University School of Business Discussion Paper A98.01.

Rosenbaum, D. I. (1994), 'Efficiency v. Collusion: Evidence Cast in Cement', Review of Industrial Organization, 9, 379-392.

Salter, W. E. G. (1966), Productivity and Technical Change, Cambridge University Press, Cambridge. 


\section{Endnotes}

1. This section is based on Das (1992) and Peray (1986). See Prentice (1998) for more details on the engineering characteristics of cement production.

2. A few plants have kilns of multiple processes but the ordering by vintage achieves the same ordering i.e. preheater/precalciner kilns are almost always newer than dry or wet process kilns in the same plant.

3. Import prices are by customs district (see Bureau of Mines (1976 - 1992) for more details) and are assigned to plants similar to the state case.

4. For fuel and electricity prices, Department of Energy (various), for wage rates see Bureau of Labor Statistics (various), Bureau of the Census ((various, a);(various, b)). See also Prentice (1997).

5. Discreteness violates the usual conditions under which duality relationships hold. However, at the kiln level, the usual relationships hold which enable use of duality.

6. Capone and Elzinga (1987) used national limestone prices. Substantially national cement industry wage rates or even broader aggregates were used by Das (various) and Rosenbaum (1994; and earlier papers). For some of these variables there are missing observations. In some cases, missing observations are replaced using data from adjacent or similar plants, similar variables, or interpolated.

7. Das (1992) used the Kiln Use Rule to infer kiln operations using plant level data. In an improvement on the methods used by Das, I corrected the capacity statistics for counter-cyclical maintenance. Not making this correction could lead to overestimating the number of kilns operating in boom periods, and underestimating the number of kilns operating in slower periods.

8. These conditions were satisified sufficiently for Bresnahan and Reiss (1990) to infer distributions of fixed costs from entry decisions and for Bertin, Bresnahan and Raff (1996) to estimate expected production rates.

9. Note that the estimate of the standard error of the distribution will, at best, provide an upper bound on the standard error of the underlying errors $\rho$. As long as the deviations from the reduced form estimate of the rents are normally distributed and 
uncorrelated with $\rho$ the estimated standard error will be an estimate of the sum of the square root of the sum of the variances for the two normal distributions. 


\section{TABLE 1}

The Algorithm for Inferring Kiln Operations from Aggregate Data

1. Determine if only one kiln per plant or if all kilns at all plants could produce the observed output. If so, then the relevant outcome was selected. If not, then

2. Compare different combinations of kiln capacities across plants with the actual output of clinker, assuming each plant followed the Kiln Use Rule.

2.a If only one combination matches the output (came within .8 or 1.05 of the actual output), the combination is selected. Otherwise

2.b The kilns that either operated in all feasible combinations were recorded as operating and

The kilns that did not operate in all of the feasible combinations were recorded as not operating.

3. The first kilns of plants known to be mothballed (or else had closed the year before, without any evidence of being scrapped) were included as not operating.

TABLE 2

Outcomes of Inferring Operations - by Plant Years

\begin{tabular}{|lr|}
\hline \hline Outcome & Number of Plant Years (1999) \\
\hline All kilns operated at each plant & 1428 \\
Not all kilns operated (known) & 139 \\
No kilns operated though available for use & 75 \\
Total number of kilns operated unknown & 357 \\
\hline
\end{tabular}

TABLE 3

Kilns in Sample by Vintage and by Process

\begin{tabular}{|lrrrr|}
\hline \hline Process/Date & Pre 1948 & $1948-1959$ & $1960-1972$ & $1972-$ \\
\hline Dry & 75 & 172 & 209 & 52 \\
Wet & 145 & 294 & 424 & 86 \\
Preheater & 6 & 29 & 20 & 487 \\
\hline \hline
\end{tabular}


TABLE 4

The Explanatory Variables

\begin{tabular}{|c|c|c|}
\hline Variable (Notation where required) & Notation & Definition \\
\hline Cement Price & $P$ & $\$$ per short ton of cement \\
\hline Limestone Price & & $\$$ per short ton of raw materials \\
\hline $\begin{array}{l}\text { Dummy - Wet, Dry, } \\
\text { Preheater/Precalciner }\end{array}$ & $\begin{array}{l}D_{w e t}, \quad D_{d r y}, \\
D_{p h / p c}\end{array}$ & $\begin{array}{l}\text { Dummy variable equal to one, if } \\
\text { the kiln is of the relevant process, } \\
\text { zero otherwise. }\end{array}$ \\
\hline Electricity Price & & \$ per million BTU of Electricity \\
\hline Fuel Price & & \$ per million BTU of Fuel \\
\hline Vintage & Vintage & 1993- Year kiln opened \\
\hline Wage Rate & & $\$$ per hour of production labor \\
\hline $\begin{array}{l}\text { Post Collapse of Union Power } \\
\text { Variable }\end{array}$ & & $\begin{array}{l}\text { 1977-1984: } 0 \\
\text { 1985-1992: }(\text { Year - 1984) }\end{array}$ \\
\hline Demand & $D$ & $\begin{array}{l}\text { Ratio of estimated actual plant } \\
\text { construction demand for the year to } \\
\text { average plant construction demand } \\
\text { for the relevant sample period. }\end{array}$ \\
\hline Price of Imported Cement & $P_{m}$ & $\begin{array}{l}\text { Average } \$ \text { per short ton of imported } \\
\text { cement at the nearest customs } \\
\text { district or river port (calculated } \\
\text { including a set of neighbouring } \\
\text { customs districts) }\end{array}$ \\
\hline Distance from Competition & $\overline{D F C}$ & $\begin{array}{l}\text { Average distance to near plants } \\
\text { (see discussion below) }\end{array}$ \\
\hline Distance from Customs District & $D F C D$ & $\begin{array}{l}\text { Miles to the nearest customs } \\
\text { district or river port, capped at } 400 \\
\text { miles. }\end{array}$ \\
\hline Dummy- Survivor, Exiter & $D_{s r}, D_{e x}$ & $\begin{array}{l}\text { Equals one if (Survivor/Exiter) } \\
\text { zero otherwise. See discussion in } \\
\text { section } 4.4 \text {. }\end{array}$ \\
\hline Exiter and Survivor Variables & $E X, S R$ & See discussion in section 4.4 \\
\hline
\end{tabular}


TABLE 5

Specification of the Variable Coefficients and Ricardian Rents

\begin{tabular}{|c|c|}
\hline Coefficient for & Specification \\
\hline & Included in the General Specification \\
\hline $\begin{array}{l}\text { Electricity } \\
\text { Fuel } \\
\text { Labor }\end{array}$ & $\begin{array}{c}\alpha_{e, w e t} D_{w e t}+\alpha_{e, d r y}\left(D_{d r y}+D_{p h / p c}\right) \\
\alpha_{f, w e t} D_{w e t}+\alpha_{f, d r y} D_{d r y}+\alpha_{f, p h / p c} D_{p h / p c}+\alpha_{v 1} \text { Vintage }+\alpha_{v 2} \text { Vintage }^{2} \\
\alpha_{\text {labor }}+\alpha_{b 1} D_{b}\left(\text { Year-1984) }+\alpha_{b 2} D_{b}(\text { Year-1984 })^{2}\right.\end{array}$ \\
\hline & Added with the Heterogeneity Specification \\
\hline $\begin{array}{l}\text { Limestone, Fuel, } \\
\text { Electricity, Labor }\end{array}$ & $\alpha_{\text {input }}+\alpha_{\text {ex,input }} D_{e x} E X+\alpha_{s v, \text { input }} D_{s v} S R$ \\
\hline & Added with the Rents Specification \\
\hline$R T_{n t}$ & $\mu_{d} D+\mu_{m} P_{m}+\mu_{d f c} D F C+\mu_{d f c d} D F C D+\mu_{v}$ Vintage $_{n}$ \\
\hline
\end{tabular}


TABLE 6

Results

\begin{tabular}{|c|c|c|c|c|}
\hline \multirow[t]{2}{*}{ Variables } & Industry & \multicolumn{3}{|c|}{ Regressions } \\
\hline & $\begin{array}{c}\text { Per short ton of } \\
\text { cement }\end{array}$ & $\begin{array}{c}\text { General } \\
\text { (1) }\end{array}$ & $\begin{array}{c}\text { Heterogeneity } \\
\text { (2) }\end{array}$ & $\begin{array}{l}\text { Rents } \\
\text { (3) }\end{array}$ \\
\hline $\begin{array}{l}\text { Limestone } \\
\alpha_{\text {limestone }}\end{array}$ & 1.42 short tons & $\begin{array}{l}3.787+* \\
(1.379) \\
2.746\end{array}$ & $\begin{array}{l}2.691+* \\
(1.252) \\
2.149\end{array}$ & $\begin{array}{c}2.762 * \\
(4.689) \\
0.589\end{array}$ \\
\hline $\begin{array}{l}\text { Electricity-Dry } \\
\alpha_{e, \text { dry }}\end{array}$ & $\begin{array}{l}0.50 \text { million } \\
\text { BTU }\end{array}$ & $\begin{array}{c}0.304 * \\
(0.483) \\
0.629\end{array}$ & $\begin{array}{l}0.820+* \\
(0.406) \\
2.022 \\
\end{array}$ & $\begin{array}{l}4.484+* \\
(2.188) \\
2.050\end{array}$ \\
\hline $\begin{array}{l}\text { Electricity-Wet } \\
\alpha_{e, w e t}\end{array}$ & $\begin{array}{l}0.43 \text { million } \\
\text { BTU }\end{array}$ & $\begin{array}{c}0.496 * \\
(0.350) \\
1.419\end{array}$ & $\begin{array}{l}1.278+ \\
(0.403) \\
3.173\end{array}$ & $\begin{array}{l}3.127+* \\
(1.794) \\
1.742\end{array}$ \\
\hline $\begin{array}{l}\text { Fuel-Dry } \\
\alpha_{f, \text { dry }}\end{array}$ & $\begin{array}{l}5.58 \text { million. } \\
\text { BTU }\end{array}$ & $\begin{array}{c}-27.631 \\
(5.449) \\
-5.071\end{array}$ & $\begin{array}{c}-26.770 \\
(5.268) \\
-5.081\end{array}$ & $\begin{array}{c}-55.849 \\
(31.404) \\
-1.779\end{array}$ \\
\hline $\begin{array}{l}\text { Fuel-Wet } \\
\alpha_{f, \text { wet }}\end{array}$ & $\begin{array}{l}5.64 \text { million } \\
\text { BTU }\end{array}$ & $\begin{array}{c}-30.652 \\
(5.716) \\
-5.362\end{array}$ & $\begin{array}{c}-31.665 \\
(5.355) \\
-5.914\end{array}$ & $\begin{array}{c}-56.819 \\
(33.089) \\
-1.717\end{array}$ \\
\hline $\begin{array}{l}\text { Fuel-Preheater } \\
\text { and Precalciner } \\
\alpha_{\mathrm{f}, \mathrm{ph} / \mathrm{pc}}\end{array}$ & $\begin{array}{l}4.09 \text { million } \\
\text { BTU }\end{array}$ & $\begin{array}{c}-34.187 \\
(5.866) \\
-5.828 \\
\end{array}$ & $\begin{array}{c}-31.578 \\
(5.527) \\
-5.714 \\
\end{array}$ & $\begin{array}{c}-69.570 \\
(35.215) \\
-1.976 \\
\end{array}$ \\
\hline $\begin{array}{l}\text { Fuel-Vintage } \\
\alpha_{\mathrm{v} 1}\end{array}$ & & $\begin{array}{c}1.128+ \\
(0.177) \\
6.386\end{array}$ & $\begin{array}{c}1.116+ \\
(0.154) \\
7.263\end{array}$ & $\begin{array}{c}1.047 \\
(0.967) \\
1.082\end{array}$ \\
\hline $\begin{array}{l}\text { Fuel- Vintage } \\
\text { Squared } \\
\alpha_{\mathrm{v} 2}\end{array}$ & & $\begin{array}{l}-0.0084 \# \\
(0.0014) \\
-5.840 \\
\end{array}$ & $\begin{array}{l}-0.0083 \# \\
(0.0013) \\
-6.541 \\
\end{array}$ & $\begin{array}{c}0.016 \\
(0.014) \\
1.163\end{array}$ \\
\hline $\begin{array}{l}\text { Labor } \\
\alpha_{\text {labor }}\end{array}$ & 0.69 hours & $\begin{array}{c}0.445 * \\
(0.608) \\
0.732 \\
\end{array}$ & $\begin{array}{c}0.823 * \\
(0.573) \\
1.436\end{array}$ & $\begin{array}{l}-5.145 \\
(3.342) \\
-1.540\end{array}$ \\
\hline $\begin{array}{l}\text { Bargaining } \\
\text { Collapse } \\
\alpha_{\mathrm{b} 1} \\
\end{array}$ & & $\begin{array}{l}-0.089 \\
(0.123) \\
-0.721 \\
\end{array}$ & $\begin{array}{l}-0.035 \\
(0.112) \\
-0.311 \\
\end{array}$ & $\begin{array}{c}0.161 \\
(0.412) \\
0.392 \\
\end{array}$ \\
\hline $\begin{array}{l}\text { Bargaining } \\
\text { Collapse }^{2} \\
\alpha_{\mathrm{b} 2}\end{array}$ & & $\begin{array}{l}-0.033 \\
(0.018) \\
-1.823 \\
\end{array}$ & $\begin{array}{l}-0.032 \\
(0.0169) \\
-1.908 \\
\end{array}$ & $\begin{array}{l}-0.035 \\
(0.060) \\
-0.590 \\
\end{array}$ \\
\hline Fixed Cost & & $\begin{array}{c}8.072 \\
(11.297) \\
0.715\end{array}$ & $\begin{array}{c}2.371 \\
(10.462) \\
0.227\end{array}$ & $\begin{array}{c}88.746+ \\
(48.482) \\
1.831\end{array}$ \\
\hline $\begin{array}{l}\text { Standard Error } \\
\text { Log Likelihood }\end{array}$ & & $\begin{array}{r}25.910 \\
-712.158\end{array}$ & $\begin{array}{r}22.226 \\
-670.866\end{array}$ & $\begin{array}{r}35.911 \\
-203.900\end{array}$ \\
\hline $\begin{array}{l}\text { Note: (1) Hetero } \\
\text { (2) *: Difference } \\
\text { (3) +: Significan } \\
\text { (4) \#: Significan }\end{array}$ & $\begin{array}{l}\text { feneity and Rent } \\
\text { from the Engine } \\
\text { ly Greater than Z } \\
\text { ly Different from }\end{array}$ & $\begin{array}{l}\text { Coefficients } \\
\text { ing Estimate } \\
\text { ro }(5 \%) \text { (Les } \\
\text { Zero }(5 \%)(\mathrm{V}\end{array}$ & $\begin{array}{l}\text { ined in Table } 8 . \\
\text { atistically Insign } \\
\text { Union-D) } \\
e^{2} \text { and Union-D }\end{array}$ & $\begin{array}{l}\text { icant }(1 \%) \\
\text { coefficients) }\end{array}$ \\
\hline
\end{tabular}


TABLE 7

Vintage Effects on Fuel Requirements

\begin{tabular}{|l|lrccr|}
\hline \hline & $\begin{array}{l}\text { Trade } \\
\text { Journal } \\
\text { Average }\end{array}$ & $\begin{array}{l}\text { Sample Size } \\
\text { Plants(Kilns) }\end{array}$ & General & Heterogeneity & Rents \\
& & & & \\
\hline Dry-1950s & 5.136 & $5(6)$ & $0.072^{*}$ & $-1.229^{*}$ & $5.695^{*}$ \\
Dry-1960s & 4.637 & $4(8)$ & -5.656 & -6.917 & $-15.165^{*}$ \\
Wet-1950s & 6.156 & $11(14)$ & $3.092^{*}$ & $3.666^{*}$ & $6.666^{*}$ \\
Wet-1960s & 5.307 & $10(13)$ & -2.635 & -2.022 & $-14.195^{*}$ \\
Wet-1970s & 4.761 & $3(5)$ & -10.047 & -9.368 & $-31.906^{*}$ \\
PH-1950s & 3.918 & $7(10)$ & $-3.463^{*}$ & $-1.143^{*}$ & $-7.056^{*}$ \\
PH-1970s & 3.351 & $15(16)$ & -16.603 & -14.177 & $-45.627^{*}$ \\
PH-1980s & 3.233 & $3(3)$ & -26.698 & -23.181 & $-60.189^{*}$ \\
\hline Note: All estimated coefficients are evaluated at the sixth year of the decade \\
$*$ Does not reject the restriction at 1\%. \\
\hline \hline
\end{tabular}

TABLE 8

Heterogeneity Adjustment and Ricardian rent Coefficients

\begin{tabular}{|c|c|c|c|c|}
\hline Coefficient & $\begin{array}{l}\text { Heterogeneity } \\
\text { Specification }\end{array}$ & $\begin{array}{l}\text { Rents } \\
\text { Specification }\end{array}$ & Coefficient & $\begin{array}{l}\text { Rents } \\
\text { Specification }\end{array}$ \\
\hline \multirow{3}{*}{$\begin{array}{l}\text { Limestone } \\
\text { (Exiter) }\end{array}$} & 10.390 & -43.173 & \multirow[t]{3}{*}{ Import Price } & -3.928 \\
\hline & $(7.078)$ & $(62.315)$ & & $(2418.3)$ \\
\hline & 1.468 & -0.693 & & -0.002 \\
\hline \multirow{3}{*}{$\begin{array}{l}\text { Electricity } \\
\text { (Exiter) }\end{array}$} & -1.936 & 8.8622 & \multirow[t]{3}{*}{ Demand } & -868.88 \\
\hline & $(0.905)$ & $(7.837)$ & & (124102) \\
\hline & -2.140 & 1.131 & & -0.007 \\
\hline \multirow[t]{3}{*}{ Fuel (Exiter) } & 6.458 & -60.293 & Average & 0.559 \\
\hline & $(8.634)$ & $(63.765)$ & Distance from & (447.402) \\
\hline & 0.748 & -0.946 & Competitors & 0.0013 \\
\hline \multirow[t]{3}{*}{ Labor (Exiter) } & -0.497 & 21.472 & Average & 0.824 \\
\hline & (1.908) & (16.014) & Distance from & (323.109) \\
\hline & -0.261 & 1.341 & $\mathrm{CD}$ & 0.0026 \\
\hline Limestone & 5.336 & 0.849 & Vintage (for & -0.860 \\
\hline \multirow[t]{2}{*}{ (Survivor) } & $(3.555)$ & (14.519) & Rents) & (4179.06) \\
\hline & 1.501 & 0.0585 & & -0.0002 \\
\hline Electricity & -0.788 & -5.277 & Vintage & 0.00025 \\
\hline \multirow[t]{2}{*}{ (Survivor) } & $(1.014)$ & (11.013 & Squared & $(56.005)$ \\
\hline & -0.778 & -0.479 & (for Rents) & 4.0 E-6 \\
\hline \multirow[t]{3}{*}{ Fuel (Survivor) } & -3.831 & 12.359 & & \\
\hline & $(5.732)$ & $(102.512)$ & & \\
\hline & -0.668 & 0.121 & & \\
\hline \multirow{3}{*}{$\begin{array}{l}\text { Labor } \\
\text { (Survivor) }\end{array}$} & -1.269 & 2.735 & & \\
\hline & $(1.191)$ & $(3.905)$ & & \\
\hline & -1.066 & 0.700 & & \\
\hline
\end{tabular}


Figure 1. The Marginal Cost Function

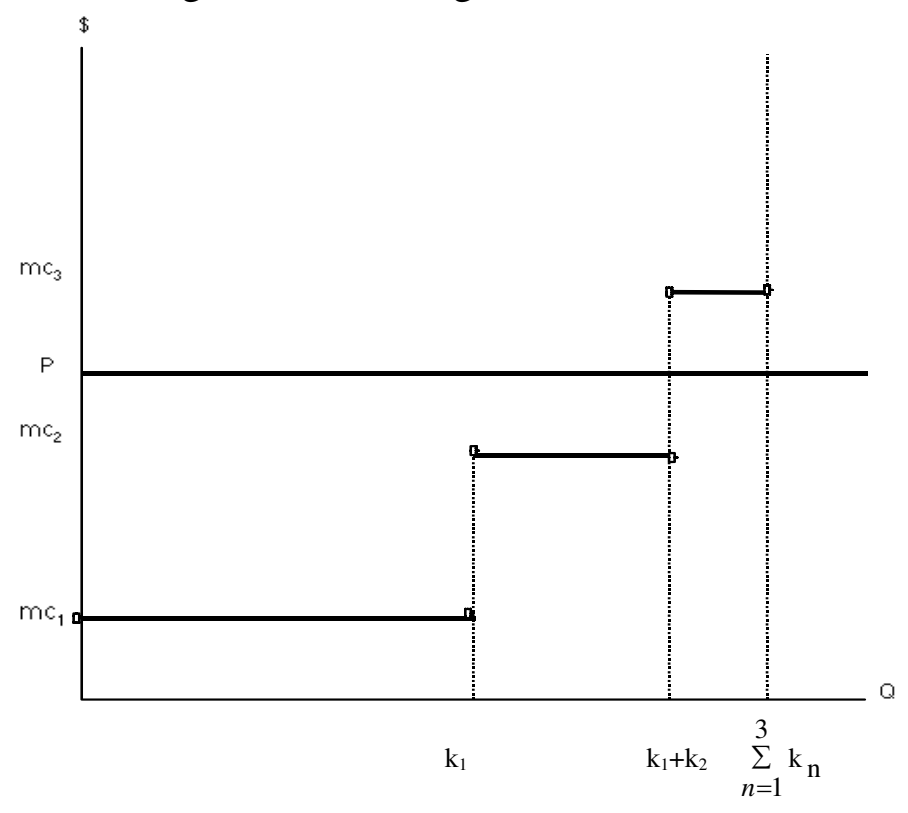

Figure 2. Distribution of Unobserved Costs

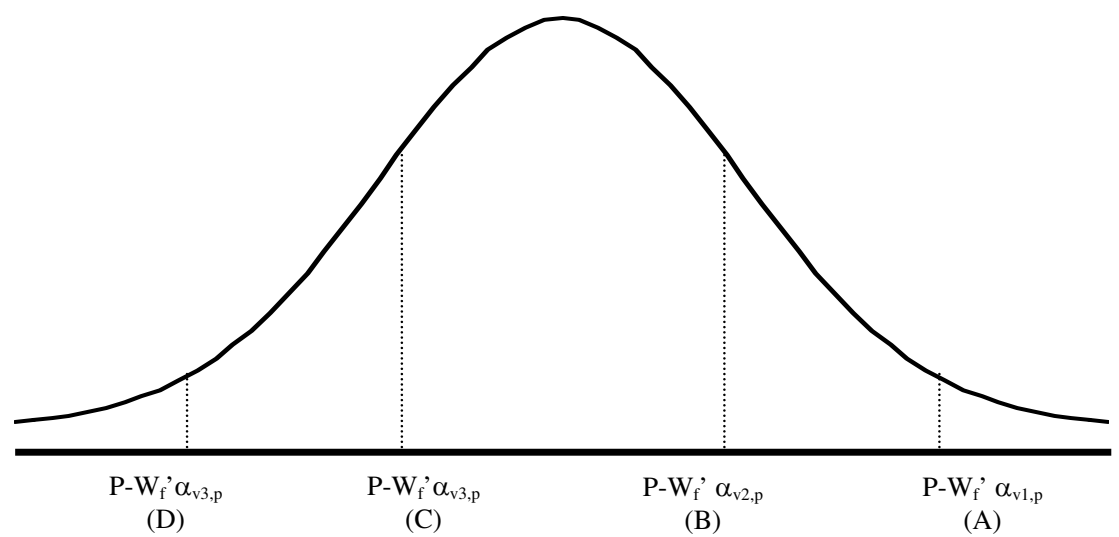

